\title{
Compreensão da Morte e do Morrer: Um Estudo com Residentes
}

\author{
Lilian Ferreira do Nascimento ${ }^{1}$ \\ ${ }^{1}$ Universidade Federal do Piauí, PI, Brasil. \\ Laís de Meneses Carvalho Arilo ${ }^{1}$ \\ ${ }^{1}$ Universidade Federal do Piauí, PI, Brasil.
}

\author{
Lívia Maria de Oliveira Silva ${ }^{1}$ \\ ${ }^{1}$ Universidade Federal do Piauí, PI, Brasil. \\ Maria Aurelina Machado de Oliveira ${ }^{1,2}$ \\ ${ }^{1}$ Universidade Federal do Piauí, PI, Brasil. \\ ${ }^{2}$ Universidade Federal do Rio Grande do Norte, RN, Brasil.
}

\begin{abstract}
Resumo: A morte é uma figura presente no cotidiano de profissionais hospitalares, uma companheira diária, invasora e sem limites, que leva à busca incessante por seu controle e cura. Quando não se sabe qual caminho seguir e o que fazer diante da complexidade do tema, pode-se experienciar diversos sentimentos e emoções. Esta pesquisa de campo, qualitativa e descritiva, objetivou compreender como residentes percebem a morte. Para tanto, 18 residentes da equipe multidisciplinar e médica de um hospital universitário responderam a uma entrevista estruturada, cujas opiniões foram analisadas com o auxílio da Análise de Conteúdo de Bardin. Os dados obtidos resultaram em 4 categorias, sendo que a categoria 2 teve 3 subcategorias. De forma geral, os residentes perceberam sua participação como uma oportunidade de fala, de expressão de sentimentos e emoções a respeito do tema. Os participantes compreendem a morte como término de vida, momento de incerteza, medo e angústia, o que desperta diferentes percepções e sentimento de impotência; bem como percebem a temática como uma oportunidade de reflexão acerca do conceito de morte digna. Observou-se a necessidade de incluir o estudo da Tanatologia nos currículos dos cursos de saúde e destaca-se que a compreensão da morte de si mesmo e do outro é pouco explorada pela literatura. Frisa-se a importância desse estudo para o incremento de produções sobre a Educação para a Morte e o Morrer, para a Psicologia e a Tanatologia, como também para o aperfeiçoamento dos programas de residências.
\end{abstract}

Palavras-chave: Tanatologia, Residentes, Hospital universitário, Morte, Pesquisa qualitativa.

\section{Understanding Death and Dying: A Study with Residents}

\begin{abstract}
Death is present in the daily lives of hospital professionals, a daily, invasive, and limitless companion, which they tirelessly seek to control and cure. People experience different feelings and emotions not knowing which way to go and what to do in the face of the complexity of this topic. This field research, qualitative and descriptive, aimed to understand how residents perceive the death. Thus, 18 residents of the multidisciplinary and medical team of a university hospital responded to a structured interview, and we analyzed their opinions with the help of Bardin's content analysis. The data obtained resulted in 4 categories, with category 2 having 3 subcategories. In general, residents perceived their participation as an opportunity to speak, to express feelings and emotions about the topic. The participants understand death as the end of life, a moment of uncertainty, fear, and anguish, awakening different perceptions and feelings of helplessness, and perceive the theme as an opportunity for reflection on the concept of dignified death. We observed a need to include the study of Thanatology in the curricula of health courses and highlight that the understanding of
\end{abstract}


the death of oneself and the other is scarcely explored in the literature. We emphasize the importance of this study for the increase of productions on Education for Death and Dying, for Psychology and Thanatology, and for the improvement of residency programs.

Keywords: Thanatology, Residents, University hospital, Death, Qualitative research.

\title{
Comprensión de la Muerte y el Morir: Un Estudio con Residentes
}

\begin{abstract}
Resumen: La muerte está presente en la vida cotidiana de los profesionales del hospital, convirtiéndose en una compañera diaria, invasiva e ilimitada, la cual se busca incansablemente su control y cura. Sin saber qué camino tomar y qué hacer frente a la complejidad del tema, se puede experimentar diferentes sentimientos y emociones. Esta investigación de campo, cualitativa y descriptiva, tuvo por objetivo comprender cómo los residentes perciben la muerte. Así en este estudio participaron 18 residentes del equipo médico y multidisciplinar de un hospital universitario quienes respondieron a una entrevista estructurada, cuyas respuestas se trataron con el Análisis de Contenido de Bardin. Los datos obtenidos resultaron en 4 categorías, de las cuales la categoría 2 tuvo 3 subcategorías. En general, los participantes percibieron su participación como una oportunidad para hablar, para expresar sentimientos y emociones sobre el tema. Los residentes entienden la muerte como el final de la vida, un momento de incertidumbre, miedo y angustia, despertando diferentes percepciones y sentimientos de impotencia, bien como perciben el tema como una oportunidad de reflexión sobre el concepto de muerte digna. Se observó la necesidad de incluir el estudio de la tanatología en los planes de estudio de los cursos de salud, y se destaca que la comprensión de la muerte de sí mismo y del otro es poco explorada en la literatura. Se enfatiza la importancia de este estudio para el incremento de producciones sobre educación para la muerte y el morir, para la psicología y tanatología, así como para la mejora de los programas de residencia.
\end{abstract}

Palabras clave: Tanatología, Residentes, Hospital universitario, Muerte, Investigación cualitativa.

\section{Introdução}

O ser humano passa por diversas etapas durante seu percurso de vida, dentre as quais a mais difícil, de acordo com Elias (2001), é a de imaginar que seu corpo ficará vagaroso, cansado e desajeitado, na qual se tem consciência de sua finitude e pode-se construir representações e significados para esse processo.

O medo da morte é comum e faz com que os indivíduos busquem se distanciar da morte desenvolvendo diversos mecanismos psicológicos de defesa, como: negação, intelectualização e deslocamento. Nega-se pensar, proíbe-se falar e a morte é afastada da vida cotidiana, visto que a imagem que se tem é a de uma morte violenta e/ou sofrida (Freitas, 2009; Oliveira \& Araújo, 2012).

Ao tratar do processo de finitude humana, destacam-se os estudos em Tanatologia; a palavra tem origem no grego a partir da união dos radicais Thanatos, que na mitologia era uma entidade masculina que representava a morte, ilustrado com asas, foice e uma urna, acompanhado por uma borboleta, que simbolizava esperança de uma nova vida; e Logos, que significa estudo (Fischer, Araújo, Wiegand, \& D’Espíndula, 2007).

Dentre os precursores do estudo tanatológico que contribuíram com seu desenvolvimento, destacam-se os filósofos Montaigne e Heidegger, o historiador Philippe Ariès, os médicos William Osler e Elisabeth Kübler-Ross e os psicólogos Aisenberg e Kastenbaum (Freitas, 2009). Uma das principais referências no Brasil, a psicóloga e doutora Maria Julia Kovács, professora do Laboratório de Estudos sobre a Morte no Instituto de Psicologia da Universidade de São Paulo, define a Tanatologia como uma "área de 
conhecimentos e de aplicação, envolvendo cuidados a pessoas que vivem processos de morte pela perda de pessoas significativas, processos de adoecimento, em decorrência de comportamentos autodestrutivos, suicídio, ou por causas externas, pela violência presente principalmente nos centros urbanos" (Kovács, 2008, p. 458).

A Tanatologia é uma ciência capaz de auxiliar e permear outras ciências, em especial as ciências humanas, sociais e da saúde, por terem interesses em comum com a temática. Outras ciências, como a saúde física, mental e espiritual, encontram na Tanatologia instrumentação para sua atuação, diante de situações de crise, confronto, de risco de morte e na administração de cuidados paliativos (Fischer et al., 2007; Färber, 2013).

A sociedade nega a morte como um processo natural no desenvolvimento humano, optando por buscar métodos e técnicas para o prolongamento da expectativa de vida e da juventude, o que acarreta perda importante das elaborações que o homem faz a respeito da morte e a torna um processo solitário, sem espaço para a expressão do sofrimento e para quaisquer rituais (Kovács, 2008; Papalia \& Feldman, 2013).

Philippe Ariès (2003) aponta que a morte já passou por diversas formas de pensamento em diferentes períodos estudados, pois não se trata de apenas um processo biológico, mas de um fato construído social e historicamente. O autor atribui ao século XX "a morte invertida", pois a morte precisava ser escondida, dado que as pessoas deixaram de morrer em casa e passaram a ser levadas para os hospitais, onde, no momento de sua morte, são colocados biombos para evitar que sejam vistas.

O tema ainda é um paradoxo. O morrer, através do avanço tecnológico das ciências, tornou-se um evento de alteração patológico do acometimento por doença grave, cujos controle e cura são buscados incansavelmente (Praxedes, Araújo, \& Nascimento, 2018). A morte é figura presente no cotidiano de profissionais hospitalares, uma companheira diária, invasora e sem limites que exige desses profissionais maior atenção e cuidado, e que é compreendida por alguns como erro e fracasso (Meireles, Feitosa, Oliveira, Souza, \& Lobão, 2019; Kovács, 2009, 2010; Vicensi, 2016). Observando tal contexto, a presente pesquisa se norteia a partir da seguinte questão: como os residentes da equipe multiprofissional e médica de um hospital universitário percebem a morte?
As discussões acerca da temática são de fundamental importância, principalmente em hospitais, na medida em que busca estimular o cuidado e o olhar humanizado, respeitando os princípios da bioética, aceitando diferenças e mediando conflitos entre a equipe, que lida com o sofrimento e a dor (Kovács, 2010). Assim, ao observar o dia a dia do profissional de saúde da residência multiprofissional e médica, percebe-se a grande exposição a situações de mortes e a dificuldade em lidar com tais perdas.

Nesse contexto, este trabalho teve por objetivo compreender como residentes de um hospital universitário percebem a morte; verificar como a temática é abordada nas diferentes equipes que integram a residência multiprofissional e médica; descrever o que profissionais de saúde pensam acerca da própria morte e da morte de familiares e pacientes; e identificar as atitudes e reações dos profissionais em relação à morte e ao morrer.

\section{Método}

\section{Tipo de pesquisa}

Trata-se de uma pesquisa de campo, qualitativa e descritiva.

A pesquisa de campo consiste na busca de informações, não só pela busca bibliográfica e/ou documental, mas também diretamente com a população pesquisada, o que demanda do pesquisador ir ao espaço onde o fenômeno ocorre para reunir as informações (Gerhardt \& Silveira, 2009; Piana, 2009).

Já a pesquisa qualitativa visa aprofundar a compreensão de determinado grupo a partir de seus significados, motivos, aspirações, crenças, valores e atitudes, coletando informações aprofundadas de acordo com aspectos da realidade (Gerhardt \& Silveira, 2009).

Por fim, a pesquisa descritiva objetiva a descrição das características de determinada população ou fenômeno ou a relação entre variáveis, utilizando técnicas padronizadas de coleta de dados (Gil, 2002).

\section{Sujeitos e local da pesquisa}

A amostra foi composta por 18 residentes dos programas multidisciplinares e clínica médica do Hospital Universitário da Universidade Federal do Piauí (HU-UFPI), matriculados no segundo ano 
de residência, das áreas de psicologia (01), enfermagem (02), farmácia (03), fisioterapia (02), nutrição (03) e clínica médica (07).

Destaca-se que as outras áreas da medicina foram excluídas pois, de acordo com a coordenação do programa, o rodízio dos residentes no segundo ano do programa de medicina ocorre fora das dependências do HU-UFPI. A amostra selecionada visou a maximização de geração de informações utilizáveis; foi não probabilística, por conveniência, de acordo com os objetivos propostos neste estudo (Gerhardt \& Silveira, 2009).

As entrevistas foram realizadas nas dependências do HU-UFPI, localizado na cidade de Teresina, no Piauí. O local escolhido para realização da pesquisa visou contribuir com o desenvolvimento do programa de residência do HU-UFPI e, consequentemente, com a qualidade da formação dos residentes atuais e futuros desta instituição.

\section{Critérios de inclusão e exclusão}

Os critérios de inclusão adotados foram: ser residente devidamente matriculado do programa multidisciplinar ou do programa médico do HU-UFPI, do segundo ano; e aceitar participar da pesquisa assinando o Termo de Consentimento Livre e Esclarecido (TCLE). Foram excluídos os indivíduos afastados do treinamento, de férias ou de licença durante período de coleta.

\section{Instrumento}

Foi utilizada entrevista estruturada contendo as variáveis sociodemográficas: sexo, idade, profissão e religião/crença. Ademais, foram inseridas perguntas abertas, elaboradas pelas pesquisadoras a partir dos objetivos traçados, tais como: Qual significado a morte tem para você?; Você pensa sobre a sua morte? Como gostaria que acontecesse?; Alguém próximo a você (familiar, amigo, cônjuge ou outros) já morreu? Quando e como reagiu?; Como reage diante da morte de um paciente?; Como tem sido abordado a temática na residência?; e Durante a sua graduação, como foi abordada a temática?

A entrevista estruturada consiste na elaboração prévia do questionário, em que constam as perguntas formuladas e totalmente estruturadas, devendo o entrevistador seguir tal roteiro predeterminado (Gomes, Oliveira, \& Alcará, 2016).

\section{Procedimentos de coleta e análise de dados}

A pesquisa seguiu as resoluções do CNS n. $466 / 2012$, 510/2016 e 580/2018, que versam sobre as pesquisas com seres humanos. Dessa forma, foi aprovada pelo Comitê de Ética em Pesquisa, bem como autorizada pela Comissão de Avaliação de Projetos de Pesquisa (CAPP/HU) e foram coletadas as assinaturas dos participantes do TCLE.

O estudo foi realizado no período de abril a maio de 2019; os participantes foram convidados a participar da entrevista via e-mail e telefone e os dados dos possíveis participantes foram adquiridos na lista disponibilizada às pesquisadoras pela coordenação da Comissão de Residência Multiprofissional (Coremu) e Comissão de Residência Médica (Coreme) do HU-UFPI.

As entrevistas aconteceram no espaço de reunião localizado na sala do Programa de Tratamento do Tabagismo, mediante agendamento, por assegurar a privacidade da amostra e por ser um local de fácil acesso aos participantes. Foram gravadas, submetidas a processo de digitação, totalmente transcritas (no formato de texto narrativo, com fala verbal, silêncio, tons de voz, choros, intervalos, entre outros), tratadas e analisadas por meio de análise de conteúdo de Bardin (Bardin, 2016).

O processo de análise de conteúdo visou definir categorias de análise em coerência com o objetivo proposto; elas foram definidas a posteriori, a partir de categorias identificadas após a escuta e leitura sistemática das entrevistas realizadas (Cavalcante, Calixto, \& Pinheiro, 2014; Bardin, 2016).

As entrevistas foram analisadas a partir da Análise de Conteúdo de Bardin, obedecendo as regras de exaustabilidade, homogeneidade, pertinência e exclusividade, sendo capaz de fornecer os dados para o desenvolvimento e a compreensão detalhada das crenças, valores, motivações e comportamentos e atitudes dos indivíduos em um contexto social específico (Câmara, 2013).

\section{Aspectos éticos}

Para melhor segurança e tratamento ético na pesquisa, as pesquisadoras informaram aos participantes sobre a natureza do estudo, além de terem tomado medidas que garantissem o bem-estar e a proteção 
do participante e seus direitos, assegurando sigilo das informações (Cozby, 2003).

Os participantes poderiam se desligar da pesquisa a qualquer momento, caracterizando parcialmente o inverso do que foi feito para a inserção na pesquisa (mediante carta assinada, procura pessoal ou telefonema), ou ainda por quaisquer imprevistos relacionados à integridade física, social e/ou psicológica do participante. Foi destacado que a recusa não traria nenhum prejuízo em sua relação com as pesquisadoras ou com a instituição.

A pesquisa apresentou como riscos a possibilidade de mobilização de alguma questão emocional, porém, este risco foi minimizado uma vez que a pesquisa foi realizada por uma psicóloga habilitada a acolher demandas mobilizadoras e a oferecer o suporte necessário para esse risco.

\section{Resultados e discussão}

É através da tradição cultural que os indivíduos adquirem concepções sobre a morte e o morrer, de modo que seus valores e crenças vão influenciar sua percepção. Isso possibilita diferentes formas de compreensão da morte, que pode ser vista como perda, ruptura, descanso ou alívio, facilitando ou dificultando o enfrentamento da morte em uma sociedade ocidental em que sua maioria a associa à tristeza e ao sofrimento (Kübler-Ross, 1998; Kovács, 1992; Martins, Cunha, Ferreira, Frizzo, \& Carvalho, 2019).

Diante da morte emergem no indivíduo diferentes sentimentos, que vão desde a raiva, a tristeza, a barganha, até a negação, podendo ser percebida de diferentes maneiras, de acordo com a história de vida, a religião, a idade, o sexo e a cultura dos indivíduos (Kübler-Ross, 1998; Kovács, 1992).

A partir do exposto são apresentados a seguir os dados obtidos nesta pesquisa. Inicialmente, apresenta-se os aspectos sociodemográficos, seguidos das categorias temáticas "Categoria 01. Significado da morte"; "Categoria 02. A morte de si mesmo e do outro"; "Categoria 03. A formação profissional e o processo de finitude"; e "Categoria 04. Atitudes e reações diante da morte".

Partindo desses pressupostos, os dados apresentados na Tabela 1 permitem melhor compreensão da amostra estudada, que apresentou um total de 18 sujeitos.
Tabela 1

Sexo, idade, profissão e religião/crença dos participantes.

\begin{tabular}{lcc}
\hline Variável-Sexo & $\mathrm{n}^{\mathrm{o}}$ & $(\%)$ \\
\hline Feminino & 13 & 72,2 \\
Masculino & 5 & 27,8 \\
\hline Variável - Idade & & \\
\hline Faixa Etária & $24-31$ anos & \\
Média & 26,6111 anos & \\
\hline Variável - Profissão & $\mathrm{n}^{\mathrm{o}}$ & $(\%)$ \\
\hline Nutrição & 3 & 16,6 \\
Farmácia & 3 & 16,6 \\
Fisioterapia & 2 & 11,2 \\
Medicina & 7 & 38,8 \\
Psicologia & 1 & 5,6 \\
Enfermagem & 2 & 11,2 \\
\hline Variável - & $\mathrm{n}^{\mathrm{o}}$ & $(\%)$ \\
Religião/Crença & 6 & 33,4 \\
\hline Cristianismo & 10 & 55,5 \\
Catolicismo & 2 & 11,1 \\
Não possui & & \\
\hline
\end{tabular}

Acerca dos itens abertos, após as respostas serem transcritas, iniciou-se a análise flutuante e, em seguida, a elaboração de categorias, a partir das quais foram destacadas das entrevistas apenas as falas que se referiam aos objetivos traçados, buscando confirmá-los ou modificá-los, organizados e intercalados com referenciais teóricos, num movimento contínuo da teoria para os dados e vice e versa.

Tais dados estão apresentados e discutidos em quatro categorias temáticas: "Categoria 01. Significado da morte"; "Categoria 02. A morte de si mesmo e do outro"; "Categoria 03. A formação profissional e o processo de finitude"; e "Categoria 04. Atitudes e reações diante da morte", sendo que a categoria 02, apresenta três subcategorias "A morte de si mesmo", "A morte do familiar" e "A morte do paciente". Elas encontram-se pormenorizadas adiante.

\section{Categoria 01. Significado da morte}

Esta categoria objetiva caracterizar como os residentes de um hospital universitário percebem a morte. Conforme as respostas dos participantes e a literatura abordada, a morte pode marcar o término do ciclo vital humano, trazendo consigo incertezas, 
medos e angústias, ou ser uma inimiga a ser temida (Barbosa, Francisco, \& Efken, 2008; Kovács, 2010; Navais, Viegas, Rodrigues, Resende, \& Teixeira, 2017), como referido nos trechos a seguir: "Morte pra mim é mais uma passagem, uma mudança do estado físico para o espiritual" (participante 17)"

Acredito que a morte ela é um processo que faz parte da vida do ser humano, é uma fase que todos nós vamos ter que passar um dia, a gente não sabe quando [risos], mas teremos que passar independente de religião e qualquer coisa, é um processo natural da vida (participante 4).

Eu acho que a morte pra mim é algo muito subjetivo, eu não, eu ainda não tenho uma percepção assim como que eu posso dizer, clara sobre a morte, eu tento usar e acreditar que é uma vontade divina que é pra tentar me sentir bem, mas eu amo a vida (participante 11).

As respostas dos participantes mostram que com a proximidade do processo de morrer emergem questões acerca de sua existência que estão atreladas a fatores sociais e que nem sempre estão claras, corroborando a literatura que destaca que o indivíduo sofre a influência de fatores como a idade, o desenvolvimento cognitivo e emocional, a dinâmica familiar, a cultura e a religião/crença em sua compreensão acerca da morte (Barbosa et al., 2008; Kovács, 2010). Como destacado nas falas a seguir: "A morte, eu penso como o fim da vida, e na concepção cristã o começo de outra vida, a gente não tem ainda compreensão. Mas pra mim é fim da vida, fim do corpo físico" (participante 1); "Eu vejo tanto sofrimento, que eu acredito que a morte seja um descanso” (participante 14).

É a terminalidade da vida, a passagem pra outro plano, mas depende de cada religião pensar pra onde a gente vai, mas eu acredito que é muito complicado, a gente não sabe se tem céu, se tem inferno realmente, a gente não sabe se depois simplesmente apaga tudo, mas a gente está aqui pra isso, todo mundo está de passagem (participante 8).

Dessa maneira, como é uma presença constante para os profissionais de saúde e apresenta diversos significados, a morte desperta diferentes percepções, sentimentos e emoções, devendo-se considerar a maneira como é compreendida ao longo de todo o desenvolvimento humano, a cultura e as situações de perdas experienciadas que auxiliam na formação do sentido sobre a finitude humana (Hohendorff \& Melo, 2009). Ou seja, ela não tem um significado único, como observa-se nos discursos citados.

\section{Categoria 02. A morte de si mesmo e do outro}

Esta categoria, dividida em três subcategorias, buscou descrever como profissionais de saúde pensam acerca da própria morte, da morte do familiar e do paciente, oportunizando o momento de fala e de expressão de sentimentos quanto ao assunto discutido.

Destaca-se que durante a busca bibliográfica observou-se uma lacuna nos estudos no que tange a compreensão da morte de si mesmo e de familiares, amigos e/ou cônjuges de profissionais de saúde.

\section{Subcategoria 01. A morte de si mesmo}

Na subcategoria 01 , os sujeitos foram questionados acerca de como pensam ou gostariam que fosse a própria morte. A literatura compreende que por meio da linguagem e de sua expressão pela fala, o indivíduo manifesta-se plenamente, expressando seus pensamentos, sentimentos e emoções (Neme et al., 2010).

Observa-se que alguns profissionais mostraram-se confusos ao pensar sobre a própria finitude. Expressaram o sentimento de impotência e fizeram um balanço de sua vida até aquele momento, tornando a morte algo mais concreto, o que pode ocasionar o medo, a fuga e/ou a negação como recursos de enfrentamento, demonstrando as dificuldades vivenciadas por eles, conforme os trechos adiante.

Acho que é uma coisa que barra, que procuro não pensar, apesar que eu pensei mais depois que minha mãe adoeceu, passei a pensar na morte das pessoas que eu amo, eu não me vejo morrendo, eu me vejo perdendo as pessoas que, são mais importantes pra mim (participante 13).

[suspiros] Na verdade eu não pensei assim especificamente eu morrendo, mas já pensei a questão do medo, a gente tem aquele medo, aquele receio, medo da morte, de sei lá, você sair um dia de casa e não voltar mais (participante 1). 
Já, pensei assim, se as pessoas iriam sentir falta de mim, e geralmente sempre que eu penso, a gente, deseja que isso seja o mais tarde possivel, mas com as experiências que a gente passa na vida, às vezes a gente vê que isso pode acontecer a qualquer momento, acontece algum acidente alguma coisa, que a gente não pode fazer nada, só tentar entender, e nessas horas a gente se agarra ainda mais nas crenças e religião pra buscar um apoio, e temos que aprender a lidar porque pode acontecer a qualquer momento (participante 9).

Diante do processo de pensar acerca da própria finitude, os profissionais expressaram diferentes compreensões que também suscitaram a discussão quanto ao direito a uma vida e uma morte digna, destacadas nos trechos a seguir:

Já pensei, e assim como eu lido com isso quase diariamente, eu vim trabalhando a ideia de como eu gostaria que isso acontecesse, apesar de saber que eu não tenho o domínio sobre isso, mas se eu pudesse tentar conduzir. Então eu acho que se eu tivesse uma doença terminal eu gostaria de ficar na minha casa, no conforto da minha família e com analgesia, e o mais, as coisas menos invasivas possiveis, se um dia isso acontecer comigo e se eu puder escolher é lógico (participante 16).

Quero morrer bem velho, bem em paz e tranquilo, na minha, e eu penso muito em eutanásia, eu acho que seria uma passagem mais interessante. Eu vejo muito sofrimento nessas mortes, bem traumáticas, $e$ na minha cabeça, na minha concepção, partir por escolha é melhor, mais natural, você estará melhor preparado para essa situação, e como falei, pra mim é um processo natural e se a gente puder escolher como passar por ele melhor ainda (participante 15).

Eu acho que se eu fosse morrer eu gostaria que fizessem o máximo por mim, não que invadissem minha privacidade no limite, mas o que pudesse ser feito de recursos médicos eu quero que seja feito, até o limite da medicina (participante 4).

Partindo do exposto pelos residentes, se faz necessário falar acerca da ortotanásia e eutanásia. A ortotanásia constitui um caminho mais equilibrado para o enfrentamento dos problemas ligados ao fim da vida, permitindo ao paciente a morte digna, sem sofrimento, deixando a evolução e percurso da doença. Já a eutanásia é considerada um meio humanístico que tem por finalidade levar à retirada da vida do ser humano por meio de uma morte indolor para aliviar o sofrimento. Ambas são ilegais no Brasil (Biondo, Silva, \& Secco, 2009; Oliveira, 2012).

Na literatura, encontramos aqueles que são pró-eutanásia voluntária, por acreditarem ser um direito legal de pôr fim à vida para propiciar a paz de espírito e deixar de lado o sentimento de culpa e/ou o medo de se sentir como um fardo ao cuidador. Esse desejo é autêntico, levando-se em consideração que o cuidado clínico nem sempre está disponível e que envolve questões socioeconômicas que o fazem parecer um sonho distante. Porém, existem aqueles que veem a eutanásia como uma opção que atribuiria pouco valor à pessoa que está morrendo e ao caminho que lhe resta nesta jornada, trazendo prejuízos não só ao paciente, mas também à família (Saunders, 2018).

\section{Subcategoria 02. A morte do familiar}

Esta subcategoria apresenta como os residentes compreendem a morte de um familiar, amigo ou cônjuge. A literatura aborda a morte do outro como a vivência da morte em vida, trazendo consigo a ambiguidade de vivenciar o luto e a possibilidade de transformação frente a morte (Freitas, 2009; Kovács, 1992).

Diante da perda, os sentimentos de medo, de saudade e de tristeza são as respostas mais comuns, podendo ocorrer também ansiedade, depressão, raiva e desespero, como pode ser observado nos trechos adiante. Tais dificuldades são intrínsecas ao processo do luto, permitindo que a perda aos poucos seja reduzida e que aqueles que perderam alguém tenham um novo mundo por descobrir e aceitar (Kovács, 1992; Parkes, 1998; Saunders, 2018).

Só mesmo parentes assim um pouco mais distante, já tive de tios e bisavós. Eu acho que dá aquele medo, porque você pensa assim: no dia anterior a pessoa estava viva e hoje não tá mais. Então eu acho às vezes a gente reflete sobre o que estava fazendo ou algumas ações que a gente toma, que a gente tem às vezes, e principalmente com os familiares, quando a gente tem uma briga, ou sei lá, é, então eu acho que eu fico mas reflexiva mesmo, e principalmente quanto às minhas ações (participante 1). 
Já perdi minha avó recentemente, tá com sete meses, aí foi mais ou menos, não foi muito sofrimento assim, na verdade foi relativamente rápido, ela tinha 93 anos. Foi então, a primeira vez que tive uma perda na família, foi a primeira vez que passei por isso, então foi difícil, mas como ela viveu bastante e ela viveu bem. então foi doloroso, mas não foi nada traumatizante, meu suporte familiar muito forte, muito forte e muito unida nesse sentido, minha mãe, meus tios, meus primos, a gente é muito unido. A gente é de conversar bastante, conversando de tudo e expressar tudo assim, não foi nada reprimido, chorei o que tive de chorar ainda choro, $e$ ainda choro assim, em data de aniversário dela, que foi esse mês, no dia do falecimento que a gente vai no cemitério visitar, e a família sempre muito unida (participante 6).

Tive meu avô, já vai fazer um ano. enquanto neta e médica acompanhando, eu acho que fui forte, mas quando ele partiu aí eu desabei mais, porque é mais difícil, a gente tem que controlar a emoção, quando tá a situação tem que passar tranquilidade pra família (participante 8).

Não é nem se acostumar, mas acabamos nos adaptando a mudança, a falta da pessoa na vida da gente, e aí continuar a viver, é o que a gente tem que fazer. Eu passei no tempo, momentos bem difíceis, tive um estresse pós-traumático, tive quadro de depressão, emagreci, chorava, e no terceiro mês percebi que tinha que me recuperar daquela fase, porque no começo foi bem difícil (participante 17).

Podemos observar a diversidade dos sentimentos, pensamentos e reações que são experienciados de maneira singular pelos participantes da pesquisa, o que corrobora as considerações trazidas na obra Perdas no desenvolvimento humano de Fukumitsu (2013), que concebe as perdas como parte do desenvolvimento humano e um dos grandes desafios da vida, devido às dificuldades intrínsecas ao processo do luto.

De acordo com Fukumitsu (2013) e Saunders (2018), as perdas são experiências que ensinam, transformam, deformam e formam; assim, percebemos que quanto mais verdadeiras forem as expressões diante deste processo, menos dolorosa se tornará a despedida, ajudando no controle e prevenção da ansiedade, da dor (física, social e emocional) e do próprio luto. Os trechos adiante ratificam tais colocações.

A gente sente muita saudade dos parentes, da conversa, mas assim, depois que morre eu não vejo assim, a gente sofrer naquele momento, sente saudade, não vou a velórios e nem a enterros, não gosto, só quando é o jeito mesmo, quando são parentes bem próximos da família, por causa das tradições e tudo, não costumo sofrer tanto, mais no dia e depois a saudade (participante 3 ).

Eu choro quando tenho que chorar, eu ajo no momento que tenho que agir, no enterro do meu avô eu chorei, eu me despedi, eu não tenho bloqueios, como eu tive com o meu pai, todo dia eu lembro dele, mas não é aquele lembrar de tristeza, é o lembrar de saudade, porque ele era muito apegado a mim e eu a ele, mas tinha consciência que ele tinha que ir, assim como eu sei que um dia tenho que ir, minha mãe tem que ir, minha vó também tem que ir (participante 5).

\section{Subcategoria 03. A morte do paciente}

Esta categoria se refere às respostas obtidas sobre o significado da morte do paciente. De acordo com Neme et al. (2010), o contato com a morte do paciente traz ao profissional a reflexão sobre a vida e os valores, além de interferir na vida pessoal e familiar.

O ser humano vive em interação com o outro, de tal modo que para o profissional de saúde diante da morte iminente do paciente é difícil não se sentir sensibilizado. Isso torna a comunicação e o contato entre paciente, família e equipe uma tortura, envolta por culpa, impotência, ansiedade, dor e luto (Saunders, 2018), conforme observa-se nas respostas dos participantes adiante.

Na verdade é uma mistura de coisas, e depende de cada caso e paciente, às vezes você se envolve mais, às vezes ocorre uma coisa de transferência com paciente, isso acontece, tem pacientes que você se apega mais, é como se tivesse perdido um amigo. Já tive pacientes que eu tive uma relação muito próxima, com a família também, e fica um sentimento de perda, tem a frustração como 
médico, que você faz o possível, mas tem que lidar com a perda, é doloroso, mas nem sempre (participante 16).

A gente lamenta muito, fica muito triste, mas com o passar do tempo a gente vai tendo que aprender a lidar com a morte né, porque se a gente absorve tudo pra si, a gente acaba adoecendo, e às vezes independente de morte ou não a gente acaba absorvendo aquele dia a dia, de se sentir incapaz e importante, e aí às vezes quando uma coisa dá errado, aí você fica "será se deveria ter feito aquilo, né?". Mas a gente acaba lidando melhor como tempo, a gente não pode se acostumar com a morte, mas a gente aprende a lidar melhor com o tempo, e com as emoções também né (participante 8).

A gente se sente incapaz, a palavra é essa, ver o paciente que a gente dá toda assistência, que cuida de cada parte, desde a higiene até o conforto a gente está ali, a enfermagem, a gente cuidar com tanto carinho da pessoa, daí entrar no plantão e a pessoa já não estar mais lá, a gente fica com aquele sentimento de que será se fez tudo, porque que isso acontece, a gente acredita muito na cura das pessoas (participante 4 ).

O Brasil ainda é imaturo em discussões e estudos sobre a morte. Devido a isso e ao fato de as doenças existirem e ameaçarem a continuidade a vida, o profissional frequentemente se sente impotente e confuso quanto às funções para as quais se preparou em sua formação, destinadas à "cura" do paciente (Arantes, 2019; Navais et al., 2017; Neme et al., 2010).

Na obra de Cicely Saunders (2018), intitulada Velai comigo, a autora destaca que mesmo assistindo a aulas sobre a morte e o morrer, discutindo-se sobre a maneira como os indivíduos tendem a lidar com a morte, auxiliando no planejamento e no tratamento de outros assuntos práticos do paciente e sua família, no momento em que se tem de lidar com essa realidade, o ser humano tende a lidar de formas diferentes. "Trata-se de uma caminhada individual ... e apesar de cada caminhada ser única, elas são levadas a cabo em um contexto semelhante" (Saunders, 2018, p. 48). Nas respostas a seguir se destacam bem esses aspectos: "Eu fico triste, lamento, alguns levo pra terapia, mas depois que saio do hospital tento não levar comigo as coisas" (participante 18); "Eu hoje na residência sofro muito com isso, quando a pessoa morre. Quando o paciente morre eu fico muito triste. Eu não queria que isso acontecesse" (participante 11).

Depende se me pega de surpresa, tem pacientes que me pegam de surpresa e eu não sei como agir, eu não sei como falar, principalmente com o acompanhante, de chegar e falar aquelas palavras de conselho, eu não consigo, me bloqueio, e tem pacientes que eu vejo como é a evolução dele e o prognóstico um pouco sombrio, aí a gente já começa a se preparar psicologicamente, mas eu sou um tipo de pessoa que começa a se apegar, porque querendo ou não a gente é profissional, mas a gente age com o coração também, não tem como não agir (participante 5)

No trabalho de Martins et al. (2019), foram entrevistados 12 profissionais de saúde (enfermeiros, fisioterapeutas e médicos) que atuavam em UTI, objetivando identificar o significado da morte de pacientes para estes profissionais. Os autores identificaram que a morte de um paciente pode ser compreendida como o fim de um ciclo e descanso aos pacientes, ou como passagem, fim de uma etapa e de missão cumprida. Nos trechos destacados adiante, isso também pode ser observado: "A gente não pode se acostumar com a morte, mas a gente aprende a lidar melhor com o tempo, entendendo que chegou o fim" (participante 8); "Eu dei todo suporte, mas é algo natural que acontece com todo mundo" (participante 9).

Eu lido muito com ventilação mecânica e a falta de ar, e a falta de ar é insuportável de se ver e principalmente de sentir, então pra mim a morte é um descanso, eu lamento, quando vejo, mas me sinto mais tranquila (participante 7).

Outro aspecto indicado pelos sujeitos foram os cuidados paliativos. Esse conceito é pouco conhecido por alguns profissionais, porém, o Brasil oferece no código de ética médica respaldo legal para a boa prática de cuidados paliativos e conta com a Constituição Federal e o direito à Dignidade da Vida que favorece tal prática, de modo que devem o paciente, sua família e equipe compreender que "a morte chegará, será aceita, mas não antecipada, ... a doença vai matá-lo, não os cuidados para 
minimizar seu sofrimento" (Arantes, 2019, p. 171). Seguem trechos que ratificam tais colocações.

Quando eu vejo que o paciente não vai ter uma resolução com a fisioterapia eu paro, eu cancelo a fisioterapia e aí não adianta fazer algo que não tem resolução, procuro dar um conforto, um sossego para o paciente (participante 7).

Eu era muito de lutar e fazer o máximo possível pra prolongar a vida do paciente ao máximo, mas à medida que a gente vai se formando entendendo o processo de doença e de cada organismo tem, o status performance que cada paciente tem, a gente vê que não adianta porque vai estar só prolongando o sofrimento do paciente, então aprendi muito quando essa questão dos cuidados paliativos, até onde insistir, que momento falar com família que os procedimentos médicos não vão trazer conforto ao paciente, podem deixar vivo mas não no melhor estado de saúde. Eu sempre avalio o estado completo do paciente, pra saber o quanto vale a pena insistir, e assim, atualmente eu não sofro mais com a questão da morte do paciente, eu sempre dou todo suporte tanto pro paciente quanto pra família, mas a morte do paciente eu tô sabendo lidar melhor, porque antes eu sempre pensava que tinha que fazer o máximo possível, que eu queria manter ele vivo o máximo possível, mas hoje eu sei saber a hora de tentar um tratamento curativo ou partir para o cuidado paliativo (participante 9).

Sempre muito doloroso, a gente se forma querendo tratar e curar, e principalmente na residência, a gente vê que nossa função não é só tratar e curar, é também trazer conforto. Então eu tive uma mudança quanto a expectativa, eu comecei a ver, principalmente dos pacientes mais graves, paliativos, que eles precisam mais de um acolhimento no sentido de diminuir o desconforto $e$ não só tentativas de persistência da vida. Busco sempre uma morte mais tranquila e digna, sem dor, sem sofrimento (participante 17).

\section{Categoria 03. A formação profissional e o processo de finitude}

Esta categoria discute a formação do profissional de saúde e o processo de finitude. Estes escolhem sua profissão "sonhando" poder ajudar e cuidar do outro, porém, durante a graduação e residência pouco ou nada é abordado sobre o processo de morte e o morrer. Apesar das grandes modificações ocorridas em nossa sociedade que nos fazem entrar em contato com o tema, a ênfase é dada ainda a métodos e técnicas para a cura e o prolongamento da vida diante dos diversos recursos disponíveis (Paula et al., 2013; Kovács, 1992; Meireles et al., 2019), conforme pode ser observado na Tabela 2.

Tabela 2

Formação profissional e a abordagem do processo de finitude.

\begin{tabular}{|c|c|c|c|c|c|c|c|}
\hline Variável Graduação & No & SIM (\%) & NÃO (\%) & $\begin{array}{c}\text { Variável } \\
\text { Residência }\end{array}$ & No & $\operatorname{SIM}(\%)$ & NÃO (\%) \\
\hline ENFERMAGEM & 2 & 50 & 50 & ENFERMAGEM & 2 & 50 & 50 \\
\hline Farmácia & 3 & - & 100 & FARMÁCIA & 3 & - & 100 \\
\hline Fisioterapia & 2 & 50 & 50 & FISIOTERAPIA & 2 & - & 100 \\
\hline Medicina & 7 & 28,58 & 71,42 & MEDICINA & 7 & 85,71 & 14,29 \\
\hline NUTRIÇÃO & 3 & - & 100 & NUTRIÇÃO & 3 & - & 100 \\
\hline PSICOLOGIA & 1 & 100 & - & PSICOLOGIA & 1 & 100 & - \\
\hline
\end{tabular}

Destaca-se na Tabela 2 que os profissionais de nutrição e farmácia não abordam o tema da morte em sua formação, nem durante a graduação, tampouco durante a residência, observando-se, assim, a necessidade de alterações e ampliação no currículo mínimo obrigatório para incluir a temática, tendo em vista que estes profissionais estão inseridos no ambiente hospitalar, onde entram em contato com esta realidade. A seguir, respostas de sujeitos que ratificam tal dado: "Não, a gente por ser área da saúde, a gente não 
trabalha isso, a gente não é preparado pra isso, mesmo sendo área da saúde e lidando muito com a morte, a gente não é preparado" (participante 11).

Não, nada, ninguém fala sobre isso. E principalmente pra nós de farmácia, porque não tem muito essa área voltada pra clínica, de ter o contato com o paciente e atender, isso tá ficando mais forte agora, antes era só o farmacêutico na farmácia e lidando com outros profissionais de saúde (participante 2).

Eu não tive a experiência até agora, a não ser aqui com você, de parar pra falar sobre isso. Em pensar que aquela pessoa era uma pessoa, que tinha família, que aí deixou de existir, que é só mais um corpo sem vida. Não aqui na residência e no setor nunca discutimos sobre isso (participante 1).

Corroborando os trechos destacados anteriormente, Praxedes, Araújo e Nascimento (2018) verificaram em seu estudo realizado com 10 docentes e 22 discentes do curso de enfermagem da Universidade do Estado do Rio Grande do Norte, que eles se sentiam despreparados para vivenciar os processos de morte e morrer no cotidiano de suas práticas, destacando a insatisfação decorrente do pouco preparo ao longo de sua formação acadêmica enquanto profissionais da saúde, acarretando sentimentos de tristeza, negativismo e impotência diante da morte e do morrer.

A morte é considerada um desafio para os que cuidam e tratam das enfermidades, o que torna necessária uma formação mais consistente sobre o tema, para capacitar de forma adequada o profissional e prepará-lo para lidar com situações de morte, com melhores condições de compreender, apoiar e amparar o paciente, a família e a equipe, proporcionando a validação de seus sentimentos e emoções (Hayasida, Assayag, Figueira, \& Matos 2014). Assim, os trechos adiante abordam a necessidade de ações que desenvolvam ou incrementem habilidades nos residentes que facilitem sua relação e atuação com o paciente e seus familiares diante do processo de morte e do morrer.

Sim, eu acho que sim, mas poderia ser mais aprofundado, que poderia ter disciplinas especificas, porque a gente lida diariamente com pessoas graves, equem não tem vivência, pra quem não trabalhou ainda chega aqui muito inexperiente, então academicamente deveria ser estimulado, isso gera conhecimento, ajuda a gente como profissional, ajuda paciente e família (participante 16).

Justamente por ser algo muito subjetivo, e relacionado a nossa religião e nossa crença, então é muito subjetivo, muito particular, e deveria até ter esse debate, até pra gente conseguir lidar com isso, como uma disciplina permanente dos $R 1$ (participante 11).

Eu acho que a residência coloca a gente mais em contato com a morte, tem a oportunidade de conviver com profissionais mais experientes, e aprende com eles, e acaba sendo bem importante, e aprendendo a como se portar, como se comunicar nessas horas, e acaba sendo bem positivo pra gente (participante 17).

Outro aspecto obtido nessa categoria foi a dificuldade em comunicar más notícias. De acordo com Bousso e Poles (2009), os profissionais de saúde apresentam essa dificuldade, cabendo a realização de treinamentos que abordem a comunicação e estimulem o respeito e dignidade em relação aos pacientes e familiares, ajudando a equipe a compreender como a experiência é vivenciada e como pode auxiliar família e paciente em suas tomadas de decisões, oportunizando um cuidado integral.

O tema dos cuidados paliativos também seria um facilitador para o ensino e aprendizagem durante o programa de residência, como apresentado nestas respostas: "Na clínica médica a gente tem mais contato por causa da equipe de paliação, a gente aprende muito, mesmo tendo coisas a melhorar (participante 3)"; "Pra mim só é abordada porque faço parte do grupo de cuidados paliativos, se eu não fizesse eu não saberia nada sobre isso (participante 4)"; “Tem uma profissional que gosta mais do tema e faz parte do grupo de cuidados paliativos, mas como a gente não tem rodízio especificamente disso, não tem aula especificamente disso (participante 6)".

Eu sei que o pessoal de geriatria eles abordam, fazem evento, sobre questão de cuidados paliativos, mas acho que já é suficiente, mas na minha opinião falta o interesse das pessoas em participar, porque sempre eles estão disponíveis, então acho satisfatório, mas falta interesse de alguns profis- 
sionais em participar, e tem gente que quer evitar ao máximo, mas precisa se preparar, e se aceitasse não sofresse tanto quanto sofrem (participante 9)

Meireles et al. (2019) analisaram a atitude de médicos e a percepção de estudantes de medicina em relação ao fim de vida; mostraram que os discentes se sentem despreparados para enfrentar a realidade; e concluíram com uma discussão acerca da tanatologia e seus desdobramentos como uma lacuna na formação em medicina, o que torna a morte questão crítica e dolorosa à profissão.

É importante destacar que já há instituições de ensino que implementam o estudo sobre a morte e o morrer, orientando seus alunos sobre a necessidade de pensar e conversar sobre o tema, que apesar de ainda ser um grande tabu, ninguém está intacto de ter que lidar com isso em algum momento da vida profissional ou pessoal (Arantes, 2019), como destacado nos trechos seguintes: "Tive o tema abordado quando se trabalhou as fases do desenvolvimento humano $e$ tanatologia" (participante 18); "Ainda bem que a gente foi privilegiado na graduação de ter esse contato” (participante 13); "Eu cheguei a fazer curso sobre tanatologia e cuidados paliativos, uma das primeiras vezes que eu tive contato com a morte" (participante 9); "Na disciplina de bioética, a gente teve na medicina legal teve tanatologia, mas na graduação foi muito pouca" (participante 3); “A partir do quarto período tem fundamentos da enfermagem, e a partir desses fundamentos tem o processo de morte e luto" (participante 4).

Eu me formei em uma instituição que tinha a disciplina de tanato na psicologia, e eu assistia algumas aulas, mas na medicina a gente não vê, não tem contato, lidar com o paciente e com ofamiliar é mais depois que a gente se forma, porque você não é preparado pra isso, e colocam na sua cabeça desde sempre que médico salva vida, a gente tá aqui pra fazero possivel colocando nossos conhecimentos à disposição das pessoas para dar qualidade de vida, seja pra elas viverem, ou morrerem com qualidade, ter dignidade pra viver e morrer também (participante 16).

\section{Categoria 04. Atitudes e reações diante da morte}

Esta categoria buscou identificar as atitudes e reações dos profissionais em relação à morte e ao morrer, sendo importante frisar que na cultura ocidental a morte é vista como tabu, às vezes sendo impronunciável, ou utilizada como sinônimo de fracasso por profissionais da saúde, o que gera tensões quanto ao pensar a própria morte e a de familiares e amigos, ou mesmo quanto ao exercício profissional (Fischer et al., 2007; Paula et al., 2013).

No ambiente hospitalar, é recorrente a dificuldade de alguns profissionais em trabalhar as questões da morte e do morrer por falta de preparo, não sabendo qual caminho seguir e o que fazer diante da complexidade do tema (Paula et al., 2013). Nos trechos destacados a seguir, isso pode ser confirmado.

Eu sou muito emotiva, e de 50 a 60\% dos pacientes que vieram a óbito eu me emociono bastante, porque eu me envolvo com pacientes e familiares, e por mais que a gente já saiba o desfecho acaba sendo uma dor, um sofrimento pra gente também, tem uns que eu não me aguento e choro mesmo, principalmente quando é inesperado (participante 17).

Eu te confesso, não sei se isso ébom ou ruim, mas eu não choro mais, eu não sei se foi uma frieza ou se é ser forte ou proteção, eu não me surpreendo com mais nada, foi uma capa assim que, uma notícia ruim eu não recebo mais como antes, de me abalar, eu fico triste e pensativa e tudo, mas passa, eu já coloquei na cabeça que tudo passa, o bomeo ruim (participante 13).

A literatura também aborda que os profissionais que lidam com os processos de morte e do morrer podem, em algum momento, experienciar ansiedade, fracasso e impotência, culpa e frustração, tristeza e/ou até mesmo desenvolver a síndrome de burnout (Hayasida et al., 2014). Tais aspectos foram citados por alguns participantes, cujas respostas estão apresentadas adiante: "Há eu fico arrasada, eu não sei lidar com a morte, eu acho que pra mim ainda é algo muito triste, eu acho que queria morrer primeiro que todo mundo, porque eu não queria sofrer" (participante 11).

Eu fico vendo se eu fiz alguma coisa de errado, fico revisando todas as coisas que eu fiz, o que eu poderia ter feito a mais para ajudar, ou se eu poderia ter feito alguma coisa a mais que poderia ter impedido daquilo acontecer, se eu deixei passar 
alguma coisa, algum resultado de exame, alguma coisa assim. É muito triste, eu fico muito triste também em ver a reação da família (participante 12).

Discussões acerca do adoecimento psíquico do profissional de saúde apontam a cada vez mais frequente tentativa de distanciamento em relação à perda de pacientes, pois mecanismos de adaptação como o distanciamento afetivo e o estabelecimento estritamente profissional são também vivenciados, sendo difícil distinguir a naturalização e a frieza. Contudo, percebe-se o aumento da carga emocional e a pressão psicológica nos profissionais (Martins et al., 2019; Meireles et al., 2019). Tais aspectos foram citados por alguns participantes, cujas respostas estão indicadas adiante.

Não vou dizer que não vou me apegar porque a gente não controla, é muito difícil, mas é aquela coisa, é ter na cabeça que ela pode partir, se a pessoa tá internada a chance de acontecer é maior que uma saudável, não que isso também não acontecer, às vezes pode acontecer com quem tá ótima, mas eu não sofro tanto, eu procuro não levar pra casa esse sofrimento, aqui eu vivo ele ... . Tem que ser como uma proteção porque se todo paciente eu for sofrer, aí vai ser complicado. (participante 13).

Eu não chego a sofrer, a gente tem muitos pacientes, e sempre está em contato com eles, então uma coisa que eu aprendi, minha mãe apesar de ser católica, ela segue mais a linha oriental do budismo, então uma coisa que eu aprendi foi a morte como processo natural tanto por parte do catolicismo quanto por lá, aí assim, eu aprendi na vida que se você acumula muito sofrimento na vida, aquilo vai acabar te prejudicando muito, então se eu for sofrer por todo paciente meu que eu perco, isso vai interferir no meu atendimento com os outros pacientes, então eu aprendi a sempre tentar não sofrer com a perda do paciente, a não ficar triste (participante 9).
O tópico seguinte contempla algumas considerações da pesquisa.

\section{Considerações finais}

Esta pesquisa foi recebida como uma oportunidade de falar, de expressar sentimentos e emoções a respeito de um tema apontado como importante, mas pouco discutido por ser concebido por alguns como angustiante. Acredita-se que ao oferecer um espaço para reflexão, foi possível contribuir para a melhoria da qualidade de vida e de trabalho, oportunizando aos profissionais a identificação de seus sentimentos e emoções e compreensão de suas defesas, facilitando um processo de autopercepção e autossuporte.

Destaca-se que a literatura ainda é escassa em estudos sobre a compreensão da morte de si mesmo e de familiares, amigos e/ou cônjuges de profissionais de saúde, existindo poucas oportunidades de expressão pública que facilitem sua vivência, pois observa-se o não reconhecimento do processo de luto do profissional de saúde.

Pôde-se observar também que a morte é percebida pelos participantes como um desafio, sendo recorrente a dificuldade de alguns profissionais em trabalhar as questões da morte e do morrer diante da complexidade do tema. Eles experienciam os sentimentos de fracasso e impotência, sendo necessário, assim, uma formação mais consistente, por meio de alterações e ampliação no currículo das residências, para incluir tais temáticas de maneira que possam capacitá-los e prepará-los para lidar com a finitude humana e demais situações advindas de sua prática no ambiente hospitalar.

Os objetivos traçados neste estudo foram alcançados, porém, verifica-se a necessidade de realização de novas investigações acerca do tema, complementando-o e/ou suplementando-o a fim de colaborar com crescimento da Psicologia, da Tanatologia, e demais áreas que se interessem pela Educação para a Morte e o Morrer e, consequentemente, contribuam para o crescimento dos programas de residências.

\section{Referências}

Arantes, A. C. Q. (2019). A morte é um dia que vale a pena viver: E um excelente motivo para se buscar um novo olhar para a vida. Sextante.

Ariès, P. (2003). História da morte no Ocidente. Ediouro.

Barbosa, L. N. F., Francisco, A. L., \& Efken, K. H. (2008). Morte e vida: A dialética humana. Aletheia, (28), 32-44. 
Bardin, L. (2016). Análise de conteúdo. Edições 70.

Biondo, C. A., Silva, M. J. P. da, \& Secco, L. M. D. (2009). Distanásia, eutanásia e ortotanásia: Percepções dos enfermeiros de unidades de terapia intensiva e implicações na assistência. Revista Latino-Americana de Enfermagem, 17(5). http://doi.org/10.1590/S0104-11692009000500003

Bousso, R. S., \& Poles, K. (2009). Comunicação e relacionamento colaborativo entre profissional, paciente e família: Abordagem no contexto da tanatologia. In F. S. Santos (Org.), Cuidados paliativos: Discutindo a vida, a morte e o morrer (pp. 193-207). Atheneu Editora.

Câmara, R. H. (2013). Análise de conteúdo: Da teoria à prática em pesquisas sociais aplicadas às organizações. Gerais: Revista Interinstitucional de Psicologia, 6(2), 179-191.

Cavalcante, R. B., Calixto, P., \& Pinheiro, M. M. K. (2014). Análise de conteúdo: Considerações gerais, relações com a pergunta de pesquisa, possibilidades e limitações do método. Informação \& Sociedade: Estudos, 24(1), 13-18.

Cozby, P. (2003). Métodos de pesquisa em ciências do comportamento. Atlas.

Elias, N. (2001). A solidão dos moribundos. Jorge Zahar Editor.

Färber, S. S. (2013). Tanatologia clínica e cuidados paliativos: facilitadores do luto oncológico pediátrico. Caderno de Saúde Coletiva, 21(3), 267-271. http://doi.org/10.1590/S1414-462X2013000300006

Fischer, J. M. K., Araújo, L. R. T. de, Wiegand, S. do C. B., \& D’Espíndula, T. C. de A. S. (2007). Manual de tanatologia. Gráfica e Editora Unificada.

Freitas, J. de L. (2009). Experiência de adoecimento e morte: Diálogo entre a pesquisa e a Gestalt-terapia. Júrua.

Fukumitsu, K. O. (2013). Perdas no desenvolvimento humano: Um estudo fenomenológico (2a ed. rev.). Digital Publish \& Print.

Gerhardt, T. E., \& Silveira, D. T. (2009). Métodos de pesquisa. Editora UFRGS.

Gil, A. C. (2002). Como elaborar projetos de pesquisa (4a ed.). Atlas.

Gomes, M. C., Oliveira, A. A. de, \& Alcará, A. R. (2016, 3-5 ago.). Entrevista: Um relato de aplicação da técnica [Resumo]. VI Seminário em Ciências da Informação: Fenômenos Emergentes na Ciência da Informação.

Hayasida, N. M. de A., Assayag, R. H., Figueira, I., \& Matos, M. D. de. (2014). Morte e luto: Competências dos profissionais. Revista Brasileira de Terapias Cognitivas, 10(2), 112-121. http://doi.org/10.5935/1808-5687.20140017

Hohendorff, J. V., \& Melo, W. V. de. (2009). Compreensão da morte e desenvolvimento humano: Contribuições à psicologia hospitalar. Estudos e Pesquisas em Psicologia, 9(2), 480-492.

Kovács, M. J. (1992). Morte e desenvolvimento humano. Casa do psicólogo.

Kovács, M. J. (2008). Desenvolvimento da Tanatologia: Estudos sobre a morte e o morrer. Paidéia, 18(41), 457-468. http://doi.org/10.1590/S0103-863X2008000300004

Kovács, M. J. (2009). Educação para a morte. In F. S. Santos (Org.), Cuidados paliativos: Discutindo a vida, a morte e o morrer (pp. 45-58). Atheneu Editora.

Kovács, M. J. (2010). Sofrimento da equipe de saúde no contexto hospitalar: Cuidando do cuidador profissional. O mundo da saúde, 34(4), 420-429.

Kübler-Ross, E. (1998). Sobre a morte e o morrer (8a ed.). WMF Martins Fontes.

Martins, L. A., Cunha, J. H. da S., Ferreira, L. A., Frizzo, H. C. F., \& Carvalho, L. B. de C. P. (2019). Significado da morte de pacientes para os profissionais de saúde em unidade de terapia intensiva. Revista Família, Ciclos de Vida e Saúde no Contexto Social, 7(4), 448-457. http://doi.org/10.18554/refacs.v7i4.3671

Meireles, M. A. de C., Feitosa, R. B., Oliveira, L. de A., Souza, H. J., \& Lobão, L. M. (2019). Percepção da morte para médicos e alunos de medicina. Revista Bioética, 27(3), 500-509. https://doi.org/10.1590/1983-80422019273334

Navais, M. C., Viegas, M. P. C., Rodrigues, R. P., Resende, R. M. de., \& Teixeira, L. C. (2017). Morte e luto: Vivências de pediatras em unidade de terapia intensiva pediátrica e neonatal nas microrregiões de Barbacena e São João Del Rei. Revista Médica de Minas Gerais, 27(supl. 1), 60-65. http://www.doi.org/10.5935/2238-3182.20170010 
Neme, C. M. B., Barbosa, C. G., Taborianski, D., Figueiredo, P. C., Kakuda, R. M., Rebelo Jr., S. L., Amaral, C. B. de A., \& Paiva, M. M. de. (2010). O contato com a morte de pacientes no serviço de oncologia hospitalar. In C. M. B. Neme (Org.), Psico-oncologia: Caminhos e perspectivas (pp. 237-285). Summus.

Oliveira, D. A. T. (2012). Dignidade da pessoa humana, cuidados paliativos e ortotanásia: A visão de um juiz. Revista Amagis Jurídica, 4(7), 33-56.

Oliveira, S. C. F. de, \& Araújo, L. F. de. (2012). A finitude na perspectiva do homem idoso: Um estudo das Representações Sociais. Revista Temática Kairós Gerontologia, 15(4), 66-83. https://doi.org/ 10.23925/2176-901X.2012v15iEspecial12p66-83

Papalia, D. E., \& Feldman, R. D. (2013). Desenvolvimento humano. Amgh Editora.

Parkes, C. M. (1998). Luto: Estudos sobre a perda na vida adulta. Editora Summus.

Paula, B. C., Silva, B. C., Deus, C. S., Lima, M. D. de O., Carolina, R., Versiani, T. C., \& Silva, K. R. (2013). A importância da tanatologia para o acadêmico de enfermagem - Artigo de revisão. Periódico Científico do Núcleo de Biociências, 3(5). http://doi.org/10.15601/2238-1945/pcnb.v3n5p58-67

Piana, M. C. (2009). A pesquisa de campo. In M. C. Piana, A construção do perfil do assistente social no cenário educacional (pp. 167-210). Editora Unesp. http://books.scielo.org/id/vwc8g/pdf/piana-9788579830389-06.pdf

Praxedes, A. M., Araújo, J. L., \& Nascimento, E. G. C. do. (2018). A morte e o morrer no processo de formação do enfermeiro. Psicologia, Saúde \& Doenças, 19(2), 369-376. http://doi.org/10.15309/18psd190216

Saunders, C. (2018). Velai comigo: Inspiração para uma vida em cuidados paliativos (F. S. Santos, Trad.). Editora FSS.

Vicensi, M. do C. (2016). Reflexão sobre a morte e o morrer na UTI: A perspectiva do profissional. Revista Bioética, 24(1), 64 -72. http://doi.org/10.1590/1983-80422016241107

\section{Lilian Ferreira do Nascimento}

Residência em Saúde - Alta Complexidade, no Hospital Universitário da Universidade Federal do Piauí (HU-UFPI), Teresina - PI, Brasil. Pós-Graduada em Tanatologia pela Faculdade Censupeg, Teresina - PI, Brasil. Pós-Graduada em Gestalt-Terapia com Ênfase em Psicoterapia pela Faculdade Inspirar, Teresina - PI, Brasil. Graduada em Psicologia pelo Centro Universitário Santo Agostinho (Unifsa), Teresina - PI, Brasil.

E-mail: liliannascimentopsi@gmail.com

(1) https:// orcid.org/0000-0003-3725-3872

\section{Laís de Meneses Carvalho Arilo}

Mestre em Saúde da Mulher pela Universidade Federal do Piauí (UFPI), Teresina - PI, Brasil. Graduada em Psicologia pela Faculdade Santo Agostinho (Unifisa), Teresina - PI, Brasil. Especialista em Gestalt-terapia com ênfase em psicoterapia pelo Centro de Formação e Aperfeiçoamento Profissional do Piauí (CFAPI), Teresina - PI, Brasil. Psicóloga Hospitalar no setor de oncologia do Hospital Universitário da UFPI. Preceptora da Residência Multiprofissional em Saúde - Alta Complexidade da UFPI. Tutora do curso de Especialização em Saúde e Comunidade da UFPI. Docente do curso de Psicologia do Centro Universitário Maurício de Nassau (Uninassau), Teresina - PI, Brasil.

E-mail: lais.arilo@hotmail.com

(1) https://orcid.org/0000-0002-1625-5601

\section{Lívia Maria de Oliveira Silva}

Residência em Saúde - Alta Complexidade, no Hospital Universitário da Universidade Federal do Piauí (HU-UFPI), Teresina - PI, Brasil. Pós-graduada em Psicanálise com crianças e adolescentes pelo Instituto de Pós-graduação e Graduação (IPOG), Teresina - PI, Brasil. Bacharel em Psicologia e Psicóloga pela Universidade Estadual do Piauí (UESPI), Teresina - PI, Brasil.

E-mail: liviamosilva@outlook.com

(1) https://orcid.org/0000-0002-4386-7662 


\section{Maria Aurelina Machado de Oliveira}

Graduada em Psicologia pela Universidade Estadual do Piauí (UESPI), Teresina - PI, Brasil. Mestre e Doutora em Psicologia pela Universidade Federal do Rio Grande do Norte (UFRN), Natal - RN, Brasil. Pesquisadora voluntária do Grupo de Estudo Psicologia e Saúde (GEPS/UFRN). Professora Adjunta no Campus Amílcar Ferreira Sobral da Universidade Federal do Piauí (CAFS/UFPI) Floriano - PI, Brasil.

E-mail:ma.aurelina@ufpi.edu.br

(D) https://orcid.org/0000-0002-1832-5490

Endereço para envio de correspondência:

Lilian Nascimento Psicologia. Rua Mato Grosso, 720, Centro Empresarial Shopping Rio Poty, Torre 2, Sala 313, Bairro Cabral. CEP: 64000-710. Teresina - PI. Brasil.

Recebido 10/02/2020

Aceito 11/02/2021

Received $02 / 10 / 2020$

Approved 02/11/2021

Recibido 10/02/2020

Aceptado 11/02/2021

Como citar: Nascimento, L. F. do, Arilo, L. de M. C., Silva, L. M. de, \& Oliveira, M. A. M. de. (2022). Compreensão da morte e do morrer: Um estudo com residentes. Psicologia: Ciência e Profissão, 42, 1-16. https://doi.org/0.1590/ $1982-3703003233879$

How to cite: Nascimento, L. F. do, Arilo, L. de M. C., Silva, L. M. de, \& Oliveira, M. A. M. de. (2022). Understanding death and dying: A study with residents. Psicologia: Ciência e Profissão, 42, 1-16. https://doi.org/0.1590/19823703003233879

Cómo citar: Nascimento, L. F. do, Arilo, L. de M. C., Silva, L. M. de, \& Oliveira, M. A. M. de. (2022). Comprensión de la muerte y el morir: Un estudio con residentes. Psicologia: Ciência e Profissão, 42, 1-16. https://doi.org/0.1590/ 1982-3703003233879 